\title{
FOOD SECURITY IN THE ERA OF SUSTAINABLE ORGANIC FARMING: A COMPARISON BETWEEN THE VISEGRAD GROUP AND INDIA
}

\section{Priya Rani Bhagat*, Róbert Magda}

\author{
Hungarian University of Agriculture and Life Sciences, Gödöllő, Hungary
}

\begin{abstract}
The agriculture industry has undergone many developments that embraced automation, agro-chemical fertilizers, genetically modified organisms etc that brought exponential growth in productivity post industrial revolution. This growth resolved the food availability issues on a global scale, but rapid climate change has brought about a shift in production practices to more sustainable organic farming techniques from the conventional methods. The climate change effects and increase in greenhouse gas emissions adversely affected the overall agricultural output. The widespread perception is that adoption of organic farming can reduce the harmful greenhouse emissions and be less damaging to the environment, although expecting the same level of productivity as conventional farming is challenging. This gradual shift can cause future food security problems such as availability and affordability of food in developing countries. This article compares and analyses such trend in the Visegrad group (V4) and India. The comparison between a group of developed nations and a developing nation is of exploratory interest because V4 countries are regarded as high-income countries and they are leaders in organic cultivation practices since the 1980s, whereas India as a developing country has seen substantial conversion of agriculture land area from conventional to organic farming in the past decade.
\end{abstract}

Keywords: organic farming, agroecology, food security, sustainable agriculture

\section{Introduction}

The global consumption and demand for food and plant-based products is rapidly increasing and it is estimated to surpass the current production capacities with the increase in population and growing dependency on renewable resources obtained from plants. Conventional farming techniques, chemical pesticides, additives, and other un-natural enhancers rapidly increased the yields from agriculture but at the same time also caused faster deterioration of soil and biodiversity of the cultivation lands, making them unfit for further production in the long term.

This realization has brought about a paradigm shift in the farming practices followed today and the wide spread opinion is that a gradual move to more eco-friendly, sustainable and organic form of agriculture helps in maintaining soil fertility, reduction in greenhouse gas emissions and overall sustainability of food production process. These sustainable organic practices are able to enhance and add to the traditional or indigenous agricultural techniques in many developing countries (Wezel et al., 2009; Wezel and Bellon, 2018). The growing population prompts the need for productive as well as sustainable agriculture (Moudrý Jr. et al., 2018). Critics of organic farming highlight the problem of lower yield in adapting organic farming but even when conventional farming provides higher output, it cannot be evidently stated that this conventional overproduction is beneficial after considering long term financial stability of farmers, exploitation in trading platforms that affect the farmers from lower output areas (Lynch, MacRae and Martin, 2011).

Yet, as is the case with many alternative methods of crop cultivation, adoption of organic farming or conversion from conventional to organic farming is very costly for most if not all small holding farmers. The expected yield is also significantly lower than conventionally produced food commodities. This also raises the prices of organic produce making organic food less affordable for the larger part of the population. Such a trend is captured and reported by the Global Food Security Index (GFSI) released annually. This particular index is a concise numeric and qualitative benchmark model which evaluates a score of maximum 100 for each of the 113 countries based on 59 distinct indicators that measure the status of food security involving developing and developed countries and it is highly accepted by the companies and academicians working in the field of food security and development (The Economist Group, 2020). It monitors and ranks 113 countries based on the 4 main parameters- affordability, availability, food quality and safety, and natural resources and resilience.

India has been ranked $71^{\text {st }}$ out of 113 countries sharing the same rank as Guatemala in the GFSI rankings for 2020. Out of the 4 main parameters under evaluation for India, the score for natural resources and resilience is the lowest at 40.8 , which highlights how the country is adapting and preparing for climate related resource risks in the future. Therefore, greater focus on climate change and resource utilization is required in India. In terms of affordability of food, India's score of 55 is 10 points behind the average score of all countries. In India the number of food-insecure people remains high, not only because of insufficient food production, but also due to lack of access to food (Panneerselvam, Hermansen and Halberg, 2010). Food availability score of India is 64.3 which is 7 points above the average. Food quality and safety is also lower than the global average of 67.6 at 59 for India according to the GFSI report.

According to a study conducted in India by Giovannucci in 2006, in the dryland areas of Southern states of India, the investment for organic inputs were relatively higher which gave yields that were lower by approximately 24 $25 \%$ than the conventional systems in the $1^{\text {st }}$ year observed under the study. Eventually by the $4^{\text {th }}$ year it was observed that the cost of organic techniques of production had reduced by $10-50 \%$ to being lower than conventional production in all cases. The yields from organic farming had increased by $10-50 \%$ also and in all cases, they were outperforming conventional systems (Giovannucci, 2006). Yet in some cases yield capacities differ with respect to diverse crops and crop patterns and depend on the environmental conditions where they undergo farming (Gomiero, Pimentel and Paoletti, 2011). 
Hence it conveyed that the resulting pros of organic farming are gradual and need consistent application for a few years before the benefits can be enjoyed. The initial transition years are difficult for cash grain cultivators while converting to organic farming and to overcome the challenges good cropping plans can lead to successful outcomes (Caldwell, Mohler, Ketterings and DiTommaso, 2014). Some of the related externalities, including resource conservation and soil fertility, may be even more valuable in the long term and ought to be a primary focus of organic development strategies (Giovannucci, 2006). However, over the coming decades, yield gaps may potentially widen due to slower plant genetic improvements in organic farming (Meemken and Qaim, 2018). The main factors that influences the yield capacity of organic farms are the soil fertility level and the quality of bio-diversity within the farm (Niggli, 2015).

In the Visegrad (V4) countries, agroecology and organic farming in particular has been accepted and supported since the 1980s with financial subsidies, technical trainings and knowledge resources provided to organic farmers to promote sustainable agriculture practices.

The graph below depicts the increase in retail sales of organic products from 2010 to 2019. There is a noticeable increase in Poland, Hungary, and the Czech Republic, while the latest data for Slovakia is unavailable - hence the stagnation in data point. The increase in sales can directly imply increase in demand from the retailers' customers and increase in the price for organic certified produce. According to food security calculations based on the Stachowiak formula done in the V4 countries by Slaboch and Kotyza in 2017, of data between 2004 to 2015, the food security trend in the Czech Republic was fluctuating with the highest spike in 2007 with similar trends in Hungary and Poland, while for Slovakia, the trend was stable across the duration observed (Slaboch and Kotyza, 2017).

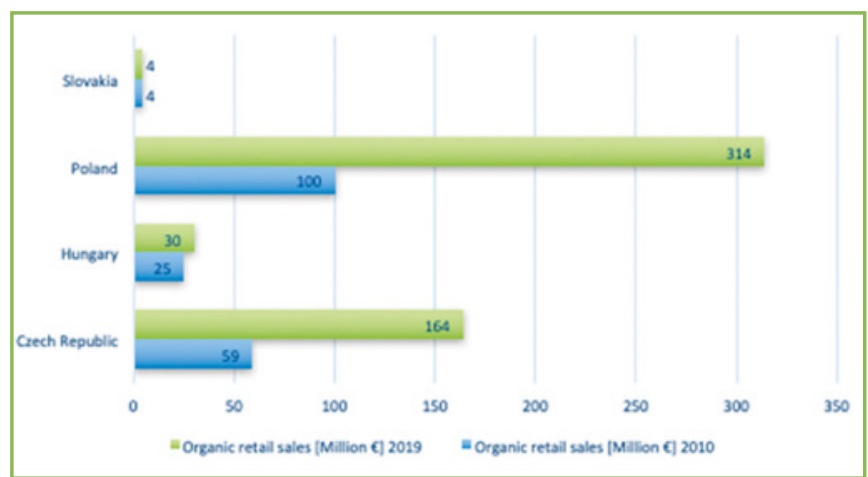

Figure 1 FiBL Statistics. Organic products retail sales between 20102019

Source: area data on organic retail sales in Europe 2010-2019, 2019

The chronology of initiatives taken by each country is stated further to provide a background in the trend to move towards organics. In the Czech Republic the foundations of the government support systems were laid with the cooperation of the Ministry of Agriculture of the Czech Republic, the Libera Association, and the PRO-BIO Association (associations of organic farmers) (Moudrý et al., 2018). The major boost was when they started releasing support funds for organic farmers in 1990 and the programme provided financial support until 1992 after which these funds were halted. These funding opportunities were reintroduced again from 1998 by the Ministry of Agriculture in Czech Republic. A number of new initiatives such as organic certification and a standard trademark to denote organic products was also introduced.

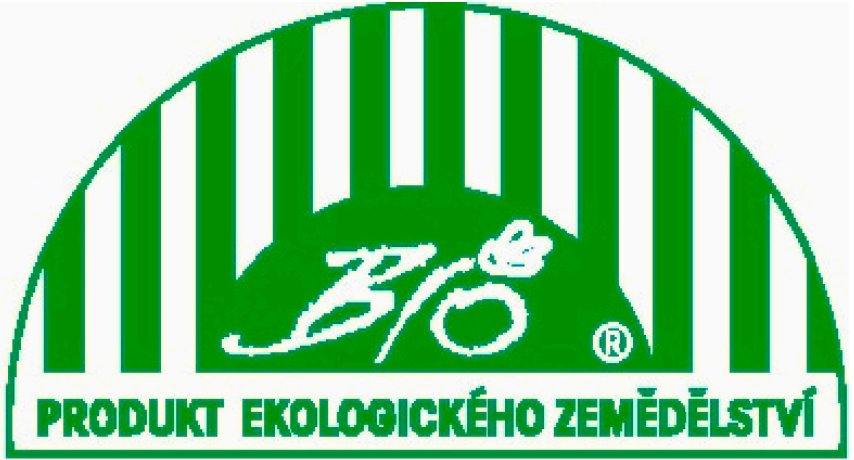

Figure 2 Bio Zebra, Czech Republic National label authorised by the Act on Organic Agriculture

Source: Global Agricultural Information Network Report, 2011

In Slovakia, the organic farming trends began in 1991. The agriculture co-operatives managed 31 farms based on organic regulatory framework which was "the rules of organic agriculture valid in the territory of Slovak Republic". The framework was based on the organic principles defined by the International Federation of Organic Agriculture Movements. The most significant increase of organic farmland was in 1997 and 1998, when the total area organically farmed raised by $55 \%$, and in that year the organic managed area represented, for the first time, more than $2 \%$ of all farmlands in Slovakia (Lehocká and Klimeková, 2019).

Since its membership accession to the European Union in 2004, the EU regulations on organic farming apply in all the certified farms of the country and financial support is provided under the EU Rural Development Programmes. Though the support for organic farming is provided throughout the whole year, it is variable and based on the type of land and crops being cultivated such as, relatively lesser for arable lands, permanent grass cover, relatively moderate amounts for medicinal plants, vegetables, aromatics and spices while the highest amount is for orchards and vineyards. The majority of the organic output produced in Slovakia is exported to the Western European countries.

In Hungary, organic agricultural movement started in the eighties with the formation of associations of farmers and other stakeholders by networking across the country. One of the most important developments was the formation of Biokultúra Association in 1987 which created a unified platform for providing standard organic agriculture practices, educational material and consultation and scientific standing for the organic movement in Hungary.

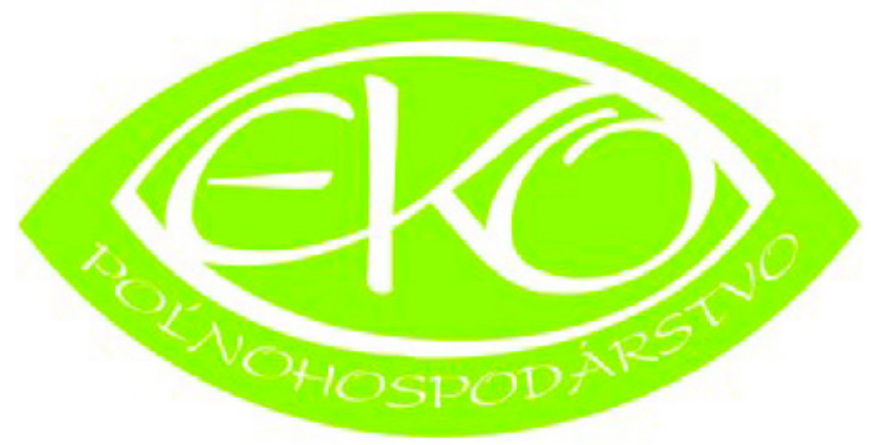

Figure 3 The Slovak Republic National label for organic products supervised by the Central Control and Testing Institute of Agriculture (UKSUP) in Slovakia Source: Organic Farming in the Slovak Republic, 2019 

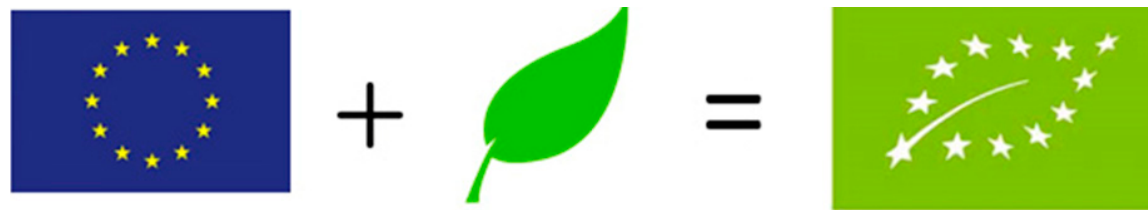

Figure 4 The European Organic certification logo Source: www.eu-organic-food.eu, 2020

Then in 1996 a supervision and inspection institute was formulated to monitor ecological impacts of agriculture named Biokontroll Hungria. In practice, Hungarian agroecology has been associated with organic agriculture since long, yet it is not limited to farm management control operations and standard certifications, but it also encapsulates good practices that are environmentally conscious for the protection and preservation of biodiversity and the ethical and social aspects of farming (Székács, Roszík, Balázs, Podmaniczky and Ujj, 2020). In 2002, the role of Hungaria Oko Garancia as the certifying and inspecting official body was granted by the Ministry of Agriculture and Rural Development of Hungary (Dezseny and Drexler, 2014). Hungary has ever since been at the forefront of scientific research and education in agro-ecological studies and contributed substantially to the body of knowledge. Following this development in 2011 the Hungarian Research Institute of Organic Agriculture (OMKi) was formed to foster further support and development in organic farming.

Hungary exports approximately $85 \%$ of its total annual organic produce as raw material or low value or unfinished, unprocessed commodities while its supermarket shelves that hold organic certified products are almost by $90 \%$ imported from other countries. Hence, there is a very small market share of organic products in Hungary which is less than $1 \%$ and these finished organic products are significantly more expensive in comparison to normal products in the same vertical. Most of Hungarian organic farmers are compensated under the European Union's EU Rural Development Programme with amounts ranging from 100 Euros to 500 Euros depending on the type of land and crops. Though, Hungary has yet to release a standard national symbol for certifying organically produced commodities and products.

Poland has not been far different from the other V4 countries and the organic movement here also began in the 1980s. Poland has the biggest land areas under agricultural use and therefore is also a leader in organic food production amongst the V4 countries. EKOLAND was the first association of organic farmers that was registered and recognised in 1989. Following which organic farming standards were established for agroecological farming in Polish farm areas and 29 early farmers got inspected and certified under the EKOLAND standards in 1990. Ever since its association with the European Union, Polish organic farms are governed and inspected under the guidelines and governance of EU standards and regulations. Despite slow improvements in the organic movement, it is facing challenges since the discontinuation of subsides for organic farmers since 2014 under the Common Agricultural Policy (CAP).

Since both Poland and Hungary do not have national standardised organic certification logos for products produced within their borders, they are certified under the European Organic logo called the "Euro-leaf" which is a symbol created by combining the official emblem of the European Union and a leaf which signifies nature and sustainable growth practices. The certification is denominated with a number of authorisations which is for example PL-EKO-04, which should be interpreted as PL- Country of origin of the product example PL for Poland, EKO-identifies that the product is organically produced and lastly the numbers represent the serial number of the certifying authority.

\section{Material and methods}

The focus of this paper is to find answers to two overarching questions:

1. Is there a difference between the rate of increase in organic farming in a developing country like India and the developed group of $\mathrm{V} 4$ countries?

2. Does the adoption of organic farming in these nations affect the overall food security of these regions? (based on data from GFSI scores).

In the scope of this study, organic farming is defined as the category of farming which is performed by utilising eco-friendly and naturally occurring methods like crop rotation according to the climate and soil condition, inputs such as animal waste manure fertilizers, machinery which does not emit greenhouse gases or emit lesser amounts of such pollutants in comparison to conventional farming. In contrast with the conventional European food system, organic farming is a low external input system, in which organic matter cycles and diversification of crops and animals are key concepts (Brzezina, Kopainsky and Mathijs, 2016).

According to the World Health Organization, food security has been defined as the condition in which "all people, at all times, have physical and economic access to sufficient, safe and nutritious food to meet dietary needs and their preferences for an active and healthy life" (World Heath Organization, 1996). Upon comparing organic and conventional farming with regards to maintaining global food security, it is necessary to consider that the concept of food security covers not just the issue of sufficient yield, but also the concepts of health, safety, and nutritional value (Ciccarese and Silli, 2016). The variables used to reach conclusive viewpoints are the land areas in hectares used for certified organic farming in each country and their corresponding GFSI scores from the years 2012 to 2020. For the purpose of performing a trend analysis, the data of the land area (in hectares) used for certified organic farming from the year 2012 to the latest available year from OECD.stat for the countries in comparison, the Czech Republic, Hungary, Poland, Slovakia, and India, was extracted. To make the comparison between India and V4, considering V4 as a single unit, the average GFSI scores is obtained and the sum total of organic land area of V4 members is used. The variables with the calculated averages and relevant data points were plotted on a time-series with the GFSI score on Y1 axis and organic land area on the $\mathrm{Y} 2$ axis.

Upon comparing Figures 2 and 3, the distinction between the trends is seen as the trend for India that the land area used for organic farming is steadily increasing in the duration of observation while the GFSI score had improved from 2012 to 2018 but even with the increase in organic land area the GSCl score for 2019 dropped significantly. The latest available data for organic land area (India) is only available until 2018 but it can be assumed based on historical trend that it would not have changed significantly from 2018 to 2019, while in the case of the V4 group there is not much deviation except for slow increase in both variables. The comparison of the trends can be interpreted as the developed and high income countries of V4 group score high on GFSI food security and have slow increasing trend in increase of organic certified farming land areas over the duration of observation. On the 


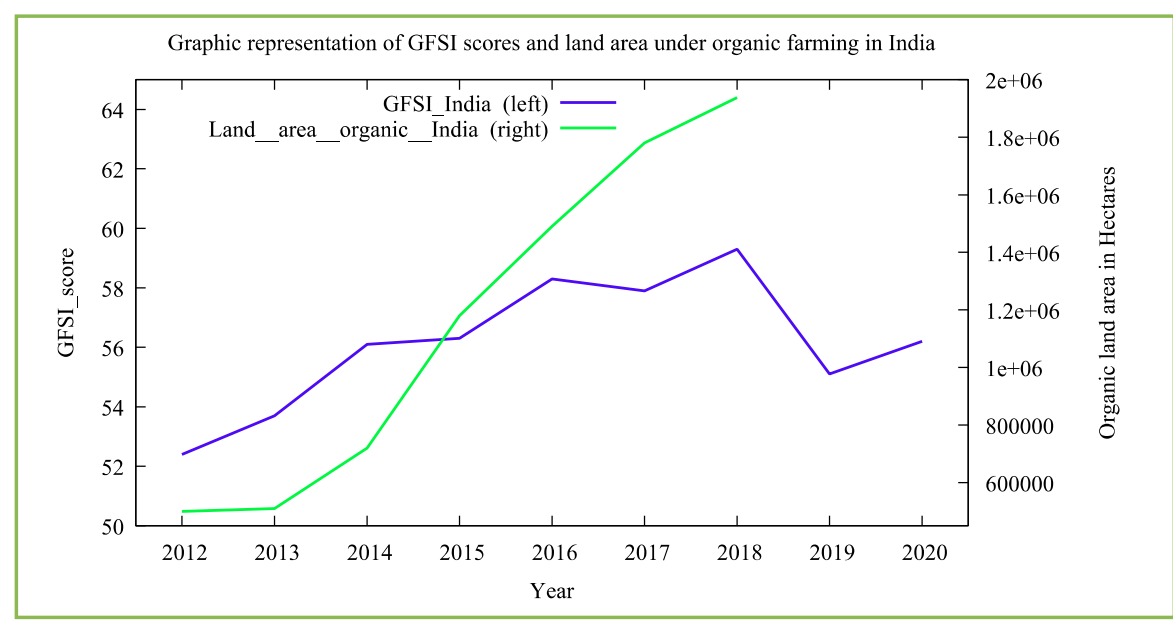

Figure 5 Time-series plot of GFSI score and land area under organic farming in India

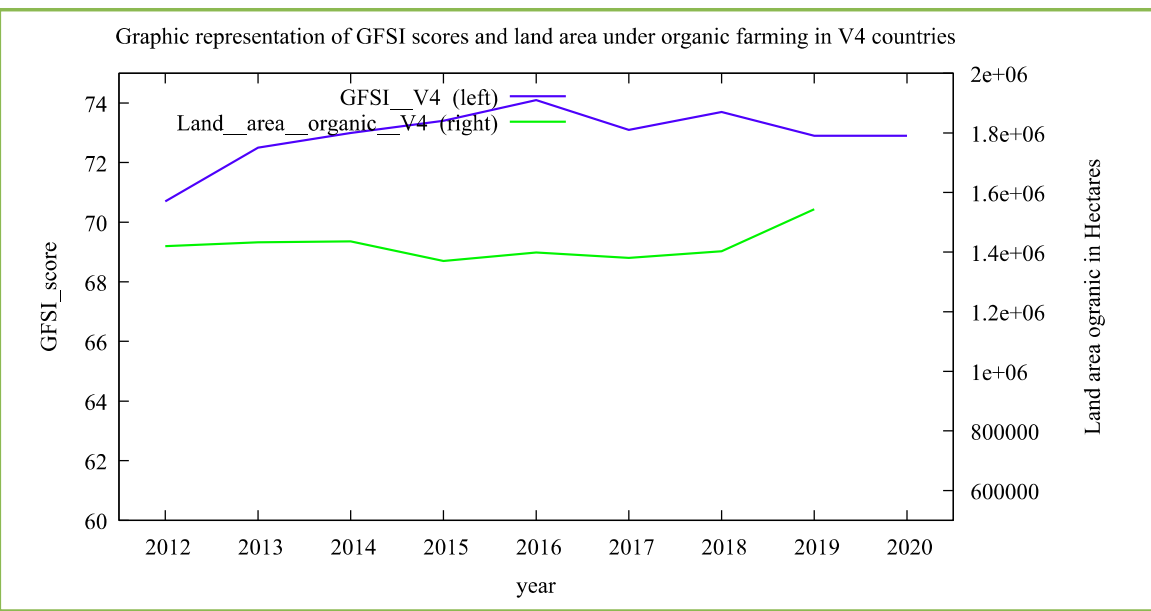

Figure 6 Time-series plot of GFSI score and land area under organic farming in V4 area

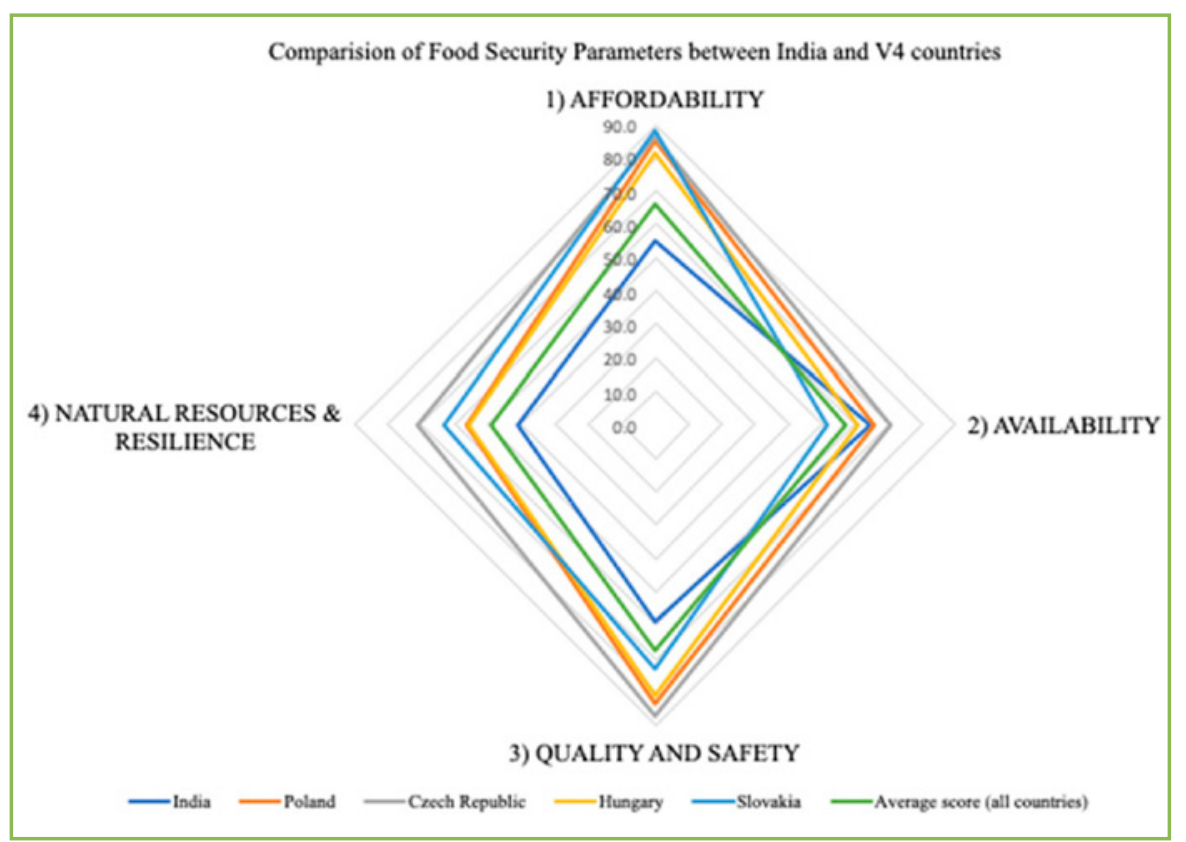

Figure 7 The 4 main food security parameters comparison other hand, a developing country such as India is consistently embracing organic agriculture by adding and converting more and more land area for organic cultivation. Yet at the same time, India is still dealing with food security problems for its population and has not experienced any easing in its food security parameters even after the large scale adoption of organic farming in the duration observed.

\section{Results and discussion}

From the above trend analysis, it can be inferred that there is a difference in the increase and rate of conversion of farmlands from conventional to organic in the high-income developed countries such as the V4 group and developing countries such as India. To answer the question if increase in organic farming can majorly affect food security in these countries, there is not enough historical food security data like GFSI scores available to assess if the correlation with organic farming is significant as the data is only available from 2012 and a longer observable duration is required to make reliable statistical analysis. Nevertheless, the food security parameters explain some of the socio-economic factors that contribute to the difference in acceptance of organic farming in the V4 member countries and India.

The socio-economic factors are explained as below:

$\square$ Indian farmers are more inclined to rapidly adopt and convert lands to organic cultivation because these crops are highly valued in the international market and there is high demand from developed countries which in turn means more income for the farmers. As can be noticed in the Figure 4, Availability in the case of India is good and hence it is natural that the focus is shifted to increasing income of the producers so that the problem of affordability of food within the country is tackled by earning more from highly demanded and better valued exports.

$\square$ In the V4 group, organic farming areas in the future are likely to reduce or remain the same due to reduction in subsidies and support for organic farming from the government. According to FiBL reports, most of the organic output is exported out as unprocessed raw material and most of the organic certified products available in retail stores and consumed by V4 group are finished products which are imported from developing countries such as India where establishing manufacturing and processing infrastructure is more economical. 


\section{Conclusions}

Many scientific critics of organic farming put the impetus on its lower yield prospects in comparison to conventional farming which may have an adverse effect on the food security conditions globally as the population will keep increasing and overconsumption is already an issue that cannot be ignored. Looking at the correlation from a socio-economic perspective in this paper, it can be implied that the changes from organic farming in relation to food security may require more time to be noticeable and the benefits may not be directly in terms of increase in yield capacities, rather the improvement is more spread across environmental and social paradigms. Food security problems gained importance and conceptualization only after 1974 and hence there is sparse amount of research done to find its correlation with other concepts and not adequate data is readily available hence further there is more scope to analysis for the correlation significance levels between these two concepts.

\section{References}

BRZEZINA, N. - KOPAINSKY, B. - MATHIJS, E. 2016. Can Organic Farming Reduce Vulnerabilities and Enhance the Resilience of the European Food System? A Critical Assessment Using System Dynamics Structural Thinking Tools. In Sustainability, 2016, pp. 1-32.

CALDWELL, B. - MOHLER, C. - KETTERINGS, Q. - DiTOMMASO, A. 2014. Yields and Profitability during and after Transition in Organic Grain Cropping Systems. In Agronomy Journal, 2014, pp. 871-880.

CICCARESE, L. - SILLI, V. 2016. The role of organic farming for food security: Local nexus with a global view. In Future of Food: Journal on Food, Agriculture and Society, vol. 4, 2016, no. 1, pp. 56-67.

DEZSENY, Z. - DREXLER, D. 2014. Country report - Hungary. Retrieved February 10, 2021, from Organic Europe: https://www.organic-europe.net/country-info-europe/ hungary/country-report.html

FiBL. 2019. Area data on organic retail sales in Europe 2010-2019. (R. I. (FiBL), Producer) Retrieved February 10, 2021, from Statistics.FiBL.org: https://statistics.fibl.org/ europe/retail-sales-europe.html

GIOVANNUCCI, D. 2006. Answering important questions about Organics in Asia. In Ecology and Farming, 2006, 39.

GOMIERO, T. - PIMENTEL, D. - PAOLETTI, M. 2011. Environmental Impact of Different Agricultural Management Practices: Conventional vs. Organic Agriculture. In Critical Reviews in Plant Sciences, vol. 30, 2011, no. 1-2, pp. 95-124.

LEHOCKÁ, Z. - KLIMEKOVÁ, M. 2019. Organic Farming in the Slovak Republic. Retrieved February 05, 2021, from Organic Europe: https://www.organic-europe.net/countryinfo/slovakia.html
LYNCH, D. - MacRAE, R. - MARTIN, R. 2011. The Carbon and Global Warming Potential Impacts of Organic Farming: Does It Have a Significant Role in an Energy Constrained World? In Sustainability, 2011, pp. 322-362.

MEEMKEN, E.-M. - QAIM, M. 2018. Organic Agriculture, Food Security, and the Environment. In Annual Review of Resource Economics, 2018, pp. 39-63.

MOUDRÝ Jr., J. et al. 2018. Agroecology Development in Eastern Europe - Cases in Czech Republic, Bulgaria, Hungary, Poland, Romania, and Slovakia. In Sustainability, 2018, pp. 1-23.

NIGGLI, U. 2015. Sustainability of organic food production: challenges and innovations. In 'Sustainable diet and food security' Symposium 2: Food production system. The Nutrition Society, 2015, pp. 83-88.

PANNEERSELVAM, P. - HERMANSEN, J. E. - HALBERG, N. 2010. Food Security of Small Holding Farmers: Comparing Organic and Conventional Systems in India. In Journal of Sustainable Agriculture, vol. 35, 2010, no. 1, pp. 48-68.

SLABOCH, J. - KOTYZA, P. 2017. Development of food security in visegrad countries after eu accession. Prague: Czech University of Life Sciences, 2017, pp. 342-348.

SZÉKÁCS, A. - ROSZÍK, P. - BALÁZS, K. - PODMANICZKY, L. - UJJ, A. 2020. Agroecological initiatives in Hungary and their Central European aspects. In International Journal of Agriculture and Natural Resources, vol. 47, 2020, no. 3, pp. 216-234.

THE ECONOMIST GROUP. 2020. Global Food Security Index. Retrieved 2 10, 2021, from foodsecurityindex.eiu.com: https://foodsecurityindex.eiu.com/

USDA Foreign Agricultural Service. 2011. Global Agricultural Information Network Report. USDA Foreign Agricultural Service, 2011.

WEZEL, A. - BELLON, S. - DORE', T. - FRANCIS, C. - VALLOD, D. - DAVID, C. 2009. Agroecology as a science, a movement and a practice. A review. In Agronomy for Sustainable Development, 2009, no. 29, pp. 503-515.

WEZEL, A. - BELLON, S. 2018. Mapping Agroecology in Europe. New Developments and Applications. In Sustainability, 2018, pp. 1-3.

WORLD HEATH ORGANIZATION. 1996. Food Safety. Retrieved February 10, 2021, from World Health Organization: https://www.who.int/foodsafety/areas work/nutrition/ en/

www.eu-organic-food.eu. 2020. ECOEUROPE Quality and Tradition EUROPEAN UNION STANDARDS. Retrieved February 10, 2021, from www.eu-organic-food.eu: http:// www.eu-organic-food.eu/en/european-union-standards/

\section{Contact address}

Priya Rani Bhagat, Hungarian University of Agriculture and Life Sciences Doctoral School of Economic and Regional Sciences, Gödöllő, Páter Károly u., Hungary; e-mail: ranibhagat93@gmail.com 